\title{
BUSINESS MODELS FOR REDUCING POST- HARVEST LOSS OF FRESH VEGETABLES
}

AN ASSESSMENT OF REUSABLE PLASTIC CRATES IN ETHIOPIA

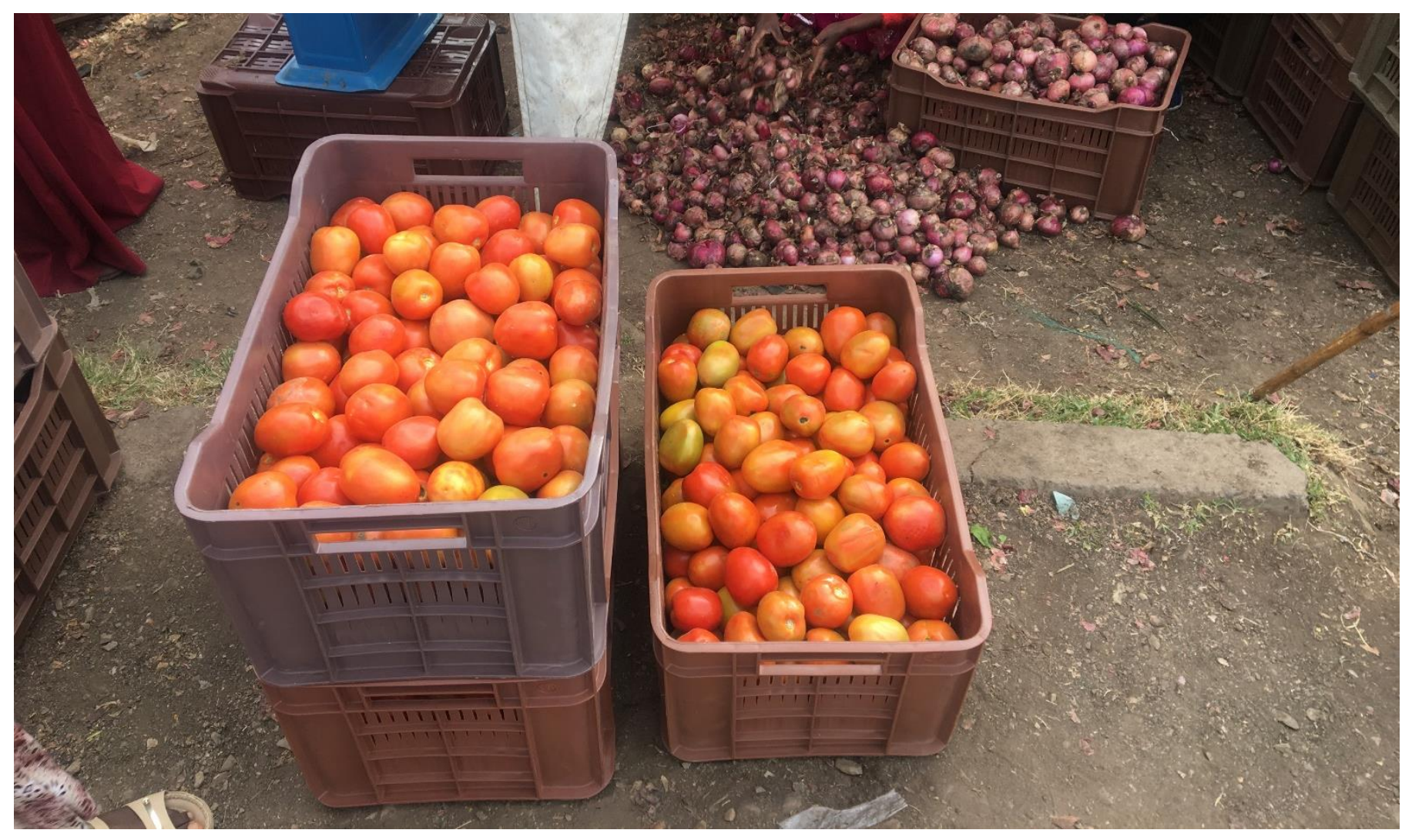

\section{GAIN Working Paper $n^{\circ} 17$}

January, 2021

Scott Hosking, Mukhtar Amin, Zerihun Zena, Teale Yalch, Stella Nordhagen 


\section{ABOUT GAIN}

The Global Alliance for Improved Nutrition (GAIN) is a Swiss-based foundation launched at the UN in 2002 to tackle the human suffering caused by malnutrition. Working with governments, businesses and civil society, we aim to transform food systems so that they deliver more nutritious food for all people, especially the most vulnerable.

\section{Recommended citation}

Hosking, S Amin M, Zena Z, Yalch T, Nordhagen S. Business Models for Reducing Post-Harvest Loss of Fresh Vegetables: An Assessment of Reusable Plastic Crates in Ethiopia. Global Alliance for Improved Nutrition (GAIN). Working Paper \# 17. Geneva, Switzerland, 2021. DOI: https://doi.org/10.36072/wp.17

\section{๑) The Global Alliance for Improved Nutrition (GAIN)}

This work is available under the Creative Commons Attribution-Non-Commercial-Share Alike 4.0 IGO licence (CC BY-NC-SA 4.0 IGO; https://creativecommons.org/licenses/by-nc-sa/4.0/). Under the terms of this licence, you may copy, redistribute, and adapt the work for noncommercial purposes, provided the work is appropriately cited, as indicated below. In any use of this work, there should be no suggestion that GAIN endorses any specific organisation, products or services. The use of the GAIN logo is not permitted. If you adapt the work, then you must license your work under the same or equivalent Creative Commons license. The contributions of third parties do not necessarily represent the view or opinion of GAIN.

\section{Acknowledgements}

This paper is based on a report produced by Dalberg Advisors. We thank all stakeholders who participated in interviews in connection with this assessment as well as Ton Haverkort for useful feedback on earlier drafts of this work. All photographs included in this document have been taken with consent for use in publications.

\section{GAIN WORKING PAPER SERIES}

The GAIN Working Paper Series provides informative updates on programme approaches, research and evaluations, and on topics of relevance for our work.

The Global Alliance for Improved Nutrition

(GAIN)

Rue de Varembé 7

1202 Geneva

Switzerland

T: +41227491850

E: info@gainhealth.org 


\section{SUMMARY}

Reducing post-harvest loss is one promising way to make nutritious foods more available, accessible, and affordable-all while improving the environmental sustainability of the food system. While viable technologies to reduce loss exist, they have limited uptake, particularly in low- and- middle income countries (LMICS). To understand how to increase the use of technologies to reduce fruits and vegetable loss, this paper examines the use of Reusable Plastic Crates (RPCs) within Ethiopia's tomato value chain. Based on stakeholder interviews and a literature review, we assess evidence on RPCs' benefits and types of business models deployed in Ethiopia and globally.

The results show that RPCs are beneficial in reducing post-harvest loss, including for tomatoes, and have wider systemic benefits for the overall value chain, including introducing standardised measurements, which may improve transaction fairness. However, adoption and use of RPCs remain low in many LMICs. We thus examine two different RPC distribution models used in a GAIN-supported programme: farmer cooperatives renting out RPCs to member farmers and traders' associations selling RPCs to their members at subsidised prices or on credit. While these low-cost models encourage uptake and adoption, they are found to be unsustainable in the long term, as the traders' associations and cooperatives are not earning the revenue needed to replace or purchase additional RPCs. However, farmers and wholesalers currently using RPCs through these groups are earning extra from the reduction in tomato losses, indicating an opportunity to adapt models to enable sustainability by charging (higher) fees. The main challenges that hinder RPCs adoption at scale are cost-related barriers to RPC ownership, market system inertia, and weak regulation. We discuss targeted interventions that could help address these challenges, including affordable, flexible financing, reducing the cost of RPCs, and using wholesalers as a value chain-agnostic entrance point to encourage wider adoption of RPCs.

\section{KEY MESSAGES}

- Reducing post-harvest loss can make nutritious foods more available, accessible, and affordable and improve environmental sustainability.

- While viable technologies to reduce loss exist, they have limited uptake.

- To understand how to increase their use, this paper examines business models for distributing RPCs within Ethiopia's tomato value chain.

- While the two business models examined encourage adoption in the short term, they are found to be financially inviable in the long term; however, changing the models by charging (higher) fees could make them viable.

- Achieving RPC adoption at scale will also require addressing cost-related barriers to RPC ownership, market system inertia, and weak regulation. 


\section{BACKGROUND AND OBJECTIVE}

Ethiopia has made significant progress in addressing child malnutrition in recent years, reducing the prevalence of childhood stunting from $50 \%$ to $37 \%$ and the prevalence of wasting from 12\% to 7\% between 2005 and 2019 (1). Despite this remarkable progress, Ethiopia's malnutrition levels remain among the highest in the world (1). For example, a recent assessment on gaps in the diets of young children in Ethiopia found moderate- or high-burden nutrient gaps for vitamin A, vitamin C, iron, zinc, iodine, folate, and calcium (2). In particular, the national food supply was found to contain inadequate amounts of vitamin $\mathrm{A}$, and there was inadequate consumption of vitamin A-rich foods among infants and young children. Among women of reproductive age, $82 \%$ were estimated to have inadequate vitamin A intake in WRA (3), and only $38 \%$ of children 6-23 m consumed vitamin A-rich foods in the past $24 \mathrm{~h}$ (4). Vitamin A deficiency has severe consequences, including poor vision, night blindness, increased susceptibility to infections, and higher mortality (5). This makes it important to consider ways to increase Vitamin A intake.

One way to do so is increasing access to, and consumption of, foods with high vitamin A content. While diet diversity in Ethiopia is in general low, the consumption of vitamin-rich fruits and vegetables is particularly low due to availability and affordability barriers. Ethiopia's per capita consumption of fresh fruits and vegetables is approximately $7 \mathrm{~kg}$ per person per year-far below the minimum level recommended by the World Health Organization and Food and Agriculture Organization (i.e., $146 \mathrm{~kg}$ per person per year). Ethiopia's per capita consumption is eight times lower than the average figure for East Africa (55 kg per person per year) and well below neighbouring countries (e.g., Sudan, at $79 \mathrm{~kg}$ per person, and Kenya at $55 \mathrm{~kg}$ per person (6).

Ensuring adequate availability and consumption of fruits and vegetables nutrients in the food supply is particularly urgent given that Ethiopia's population is projected to nearly double between 2020 and 2050 (7). One option for doing so is reducing postharvest loss (PHL) - loss that happens when food is lost along the value chain after production but before reaching the consumer (8), for example during storage, processing and transport. About $25 \%$ of fresh fruits and vegetables produced in subSaharan Africa are lost or wasted (9). ' Global estimated food losses in 2017 were enough to feed about 940 million adults (12), and reducing PHL has the potential to reduce the share of the population at risk of hunger by $11 \%$ and child undernutrition by $4 \%$ by 2050 (12). Reducing PHL throughout value chains for micronutrient-rich produce could be an effective way to make nutritious food more accessible in Ethiopia, helping address micronutrient deficiencies, and would also help improve the environmental sustainability of the food system (13).

1 There is significant variation by crop and region, and no clear consensus on the magnitude of loss $(10,11)$. 
GAIN has thus worked to reduce PHL across value chains for nutritious foods over the past four years through the Postharvest Loss Alliance for Nutrition (PLAN) programme (14). PLAN brings together stakeholders from public and private sectors to work on PHL reduction across nutritious food value chains. After an assessment of the tomato, papaya, and mango value chains, PLAN's Ethiopia chapter (E-PLAN) prioritised tomatoes for PHL reduction; PHL of tomatoes in Ethiopia is high, at about $20-35 \%$, and spread across value chain segments. It was estimated that if $25 \%$ of loss in the tomato value chain were prevented, it would make available enough Vitamin A to meet the nutrient requirements of 20,000 pre-school children every day (15).

While many food loss-related interventions have focused on on-farm improvements, specifically on crop storage (8), a considerable amount of PHL in Sub-Saharan Africa occurs after food leaves the farm, during the distribution, packaging, and processing stages (16). E-PLAN thus targeted the middle part of the value chain (particularly transport and distribution stages). One of E-PLAN's main interventions was introducing Reusable Plastic Crates (RPCs) for use in storing and transporting tomatoes: based on FAO analysis (17), the use of these crates in Ethiopia was estimated as being able to eliminate 5-10 percentage-points of loss when compared to wooden crates. E-PLAN thus distributed 19,000 RPCs to farmer cooperatives in Rift Valley tomato-producing areas and to traders' associations based in Addis Ababa. While providing subsidised RPCs worked as an initial introduction to the technologies within the project, the subsidy made it unclear whether they were commercially viable for continued use within Ethiopia and, if so, under which business models. A recent financial modelling study of PHL-reduction technologies, including RPCs, in Nigeria has indicated that viable business models for PHL-reduction technologies are achievable-but also not guaranteed (18).

Significantly reducing PHL, however, would require widespread and sustained adoption of RPCs, which entails that their adoption and ongoing use must be financially viable for users. Based on prior research and stakeholder interviews, this working paper examines business models used to distribute RPCs within Ethiopia and elsewhere, with particular attention to their financial viability. It also examines the benefits of RPCs and challenges limiting their uptake. The results are then discussed in terms of their implications for future interventions to sustainably increase the uptake of RPCs, a key PHL-reduction technology.

\section{METHODOLOGY}

This paper assesses three topics related to the distribution of RPCs in tomato value chains in Ethiopia. First, the paper analyses the benefits of RPCs: the extent to which they reduce loss in the tomato value chain as well as potential secondary effects that RPCs may have on system fairness and efficiency. Second, it assesses business models used to distribute RPCs in Ethiopia and compares them to global best practice. Finally, 
the paper identifies challenges to wider RPC uptake amongst informal tomato value chain actors across Ethiopia. All three analyses are based on stakeholder interviews and review of prior research. The paper only considers RPC distribution, not other EPLAN activities.

In total, 22 stakeholders were interviewed in September-October 2020, including four from government institutions, three from development agencies, four from farmer cooperatives and trader associations, six business leaders or value chain actors, and five university researchers. The interviewees included the E-PLAN cooperative union intermediaries, Meki-Batu and ODA Agro-Industry, as well as two traders' associations, Piazza and Arada S.C. For E-PLAN participants, the interviews covered the basics of the respondent's position and organisation, their use of RPCs and similar technologies, the benefits and challenges they perceive with the use of RPCs, and the details of the business model they use for accessing or distributing RPCs. For experts, the interviews covered their expertise with RPCs, their understanding of the evidence base on RPCs and similar technologies, perceived benefits and challenges, alternative technologies, and business model options and their viability. For E-PLAN partners (e.g., those with development agencies), the interviews covered their experience with EPLAN and with RPCs, perceived benefits and challenges of RPCs, and views on viable alternatives to RPCs.

To assess the business models, we mapped out four key modalities in relation to the RPCs distributed through E-PLAN: ownership, usage, revenue models, and risk management mechanisms. In analysing each of these elements, we sought to answer three key questions: (I) who are the RPCs owners and users? (ii) how do RPCs circulate along the value chain as they pass from owners to users? and (iii) who benefits from using the RPCs?

Before presenting the main results of the assessment, the next section describes Ethiopia's tomato value chain and PHL within it. Subsequent sections then examine RPCs as a viable intervention to reduce PHL and the different models used to distribute them within E-PLAN and their viability. Additional challenges to RPC uptake in Ethiopia are then considered before the results are discussed in terms of their implications for future efforts to reduce PHL.

\section{ETHIOPIA'S TOMATO VALUE CHAIN}

Tomatoes are widely produced across Ethiopia, with estimated total annual production of around 60,000 tonnes $^{2}$ and more than 277,000 farmers engaged in the

\footnotetext{
2 Total tomato production is extrapolated from Central Statistical Agency of Ethiopia (CSA) data, which represents the Meher season from September to February. The Meher season covers the complete third tomato harvest season in the last part of the year and part of the first harvesting season in the beginning of the year but excludes the second harvesting season over the summer. Based on interviews with industry expert, the first harvesting season is typically the most productive, the second the least productive, and productivity in the last season nears that of the first season. By
} 
market (19). However, overall production and yields have declined over the past five years, largely due to lack of access to proper and affordable pesticides and fertilisers to control disease and pests: the cost of inputs increases by about $12 \%$ every year, according to the Central Statistical Agency of Ethiopia, and the price of appropriate stakes has increased by $\sim 30 \%$. These cost increases have led some smallholder farmers to exit the market.

Tomato production is concentrated in the Oromia and Amhara regions, which contribute over $75 \%$ of the total output. Most of the tomato production in the Rift Valley region of Oromia flows to Addis Ababa, while tomatoes produced in distant regions flow to more local markets. There is year-round demand for tomatoes, particularly around the fasting season, as they are used in many dishes central to the Ethiopian diet. They are a good source of Vitamin A, with 100 grams fulfilling $17 \%$ of the daily recommended intake, and also supply a similar amount of vitamin C $121 \%$ of recommended daily intake) (20).

Ethiopia's tomato value chain can be divided into smallholder ( $<1$ hectare) value chains and value chains involving producers with medium to large landholdings (>2 hectares). Smallholder value chains display higher degrees of fragmentation, while value chains involving producers with larger landholdings are relatively streamlined. For smallholders, tomatoes are stored on farm, and bringing them to market is dependent on availability of traders for transport, which is often unpredictable. For larger producers, there is more predictability in terms of transport, as they produce sufficient quantities to entice transporters to collect tomatoes from the farm immediately after harvest. As such, first-mile transport to an aggregation point is also absent from the large-landholding value chains.

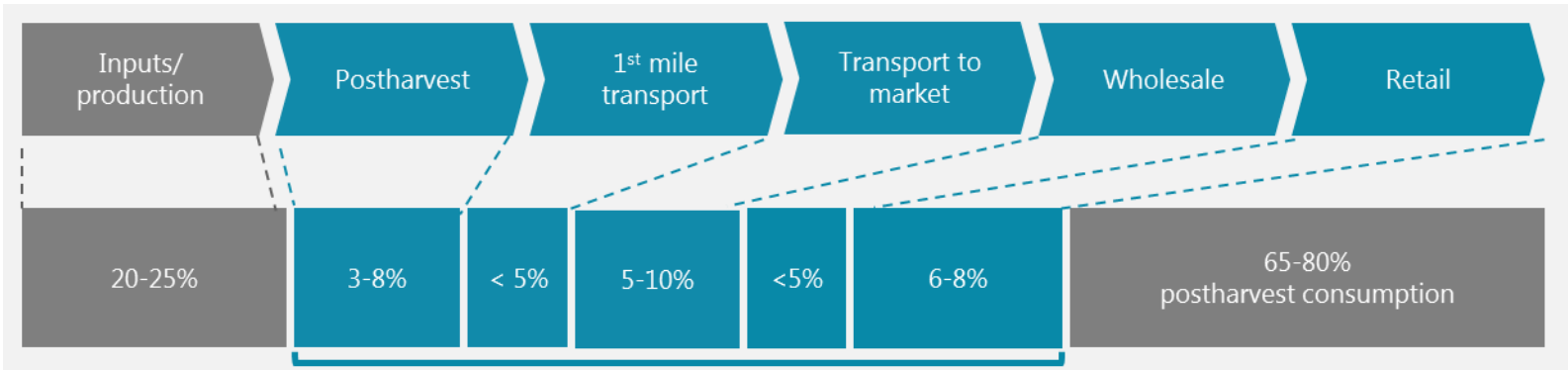

Estimated postharvest loss 20-35\%

Figure 1. Outline of postharvest losses at each stage in the tomato value chain

Across the tomato value chain, postharvest losses are estimated to be between 2035\%. As illustrated in Figure 1, this loss occurs throughout the value chain's six stages: inputs and production, postharvest, first-mile transport, transport to market, wholesale, and retail. Loss is largely concentrated in postharvest, transport, and retail segments. These losses occur as follows:

multiplying the CSA estimate by 2.25 , we arrive at an estimated production figure for the most and the least productive season $(2.25 \times 27.000=\sim 60.000$ tonnes $/$ annum $)$. 
1. Inputs/production ${ }^{3}$ : Loss during production can reach as high as $20-25 \%$ and is mainly driven by pests and diseases, which are difficult for farmers to manage due to increasing input costs. Furthermore, most farmers do not use best practices for storage and maintenance but rather resort to the use of t-shirts, sacks, and low-quality wooden crates to store harvested tomatoes. This leads to significant spoilage and loss.

2. Postharvest: The postharvest segment is defined as the time in which tomatoes are stored on farm prior to collection or transport to an aggregation point. This on-farm PHL is around 3-8\%--being higher among smallholder farmers and lower at larger farms. This loss is primarily due to high sun exposure and poor handling. Few farmers have access to appropriate storage (e.g., cold rooms) and instead leave tomatoes in suboptimal conditions for up seven to eight hours on larger farms and one to two days for smaller farms.

3. First-mile transport: Smallholder farmers often transport most of their tomatoes to local markets or local aggregation points targeting larger urban markets. Modes of transportation used include wheelbarrows or animal-drawn carts, and farmers and transporters alike have few incentives to care for the quality of the tomatoes, leading to poor packaging and handling. Still, loss in this segment is limited due to the short distances involved, rarely exceeding $5 \%$.

4. Transport to market: During transport to farther, more urban markets, loss can reach as high as 5-10\%, caused primarily by poor crating options, overpacking, and heat stress. Transportation time ranges from 3 hours (Meki to Addis) to 12 hours (Meki to Eastern Ethiopia). Tomatoes are sold in bulk to wholesalers, and neither brokers nor transporters have strong incentives to maintain quality. Transporters receive a flat fee for their services, regardless of the condition of the produce upon arrival, and are thus motivated to deliver produce as fast as possible, leading to poor handling and suboptimal transportation conditions.

5. Wholesale: Tomatoes typically spend less than five hours at this stage, as wholesalers in large markets are motivated to sell their produce as fast as possible to make room for new produce. This high turnover rate minimises loss at this stage, which rarely exceeds $5 \%$. While tomatoes are often moved quickly in a chaotic environment, causing some spillage, there is very little damage to the tomatoes. Some of the mechanical damage occurring at this stage, however, is carried over to retailers as it is hidden within the crates they purchase.

6. Retail: Loss at retail level is primarily a result of tomatoes' limited shelf-life and the relatively long period that they spend at retailers (up to five days). Retailers

${ }_{3}^{3}$ While production loss is relevant to understanding value chain drivers and dynamics, it is out of scope of the rest of this paper, which focuses exclusively on postharvest loss. 
generally care for the quality of their tomatoes, as they can sell higher quality tomatoes for up to twice the price of bad tomatoes; however, most retailers lack access to appropriate storage to protect tomatoes from high temperatures and direct sun exposure. As a result, 6-8\% of tomatoes are lost on average due to spoilage, and retailers are forced to lower the price of tomatoes as they deteriorate over time.

The numbers noted above are averages: parts of the value chain have much higher or much lower loss estimates. For example, in markets far from Addis Ababa, loss at retailers can reach levels of $40-50 \%$, as transportation time to market is longer and storage options are limited. At the other extreme, some value chains have been optimised to limit loss by the presence of a premium off-taker. For example, the Meki Batu Union directly supplies Ethiopian Airlines for its catering needs and thus uses cold chain facilities at each value chain stage to achieve low losses and sufficient quality. While this is likely infeasible for the mass consumer segment, it provides an example of how PHL can be reduced significantly with the right use of technology.

\section{CHARACTERISTICS AND BENEFITS OF RPCS}

In addition to higher-tech interventions such as improving processing and increasing the use of effective cold storage technologies, using plastic crates offers a fairly simple, low-cost, and rapid way to reduce losses. Currently, most Ethiopian tomato farmers use wooden crates for transport to market and a range of bags, sacks, and crates for first-mile transport. Wooden crates carry bacteria and organisms and limit air circulation, which accelerates spoilage. Additionally, stacking of non-uniform crates causes mechanical damage. In contrast, reusable plastic crates (RPCs) can decrease both nutritional and physical loss by eliminating overloading with better stackability and nestability, improved aeration, and smoother sides and edges that reduce mechanical damage. In addition, because they tend to be smaller, RPCs are easier to handle, load, and maintain. Figure 1 summarises the benefits of RPCs. 


\begin{tabular}{|c|c|c|c|}
\hline & $\begin{array}{c}\text { Reusable Plastic Crates } \\
\text { (RPCs) }\end{array}$ & Wooden Crates & \multirow{2}{*}{$\begin{array}{l}\text { The lower weight of plastic crates } \\
\text { helps minimize damage during } \\
\text { handling as they are easier to } \\
\text { carry and load }\end{array}$} \\
\hline Status & $\begin{array}{l}\text { A recent introduction to the } \\
\text { marker by dev't partners, } \\
\text { coops and associations }\end{array}$ & $\begin{array}{l}\text { Most known and used in the } \\
\text { market }\end{array}$ & \\
\hline Crate weight & $2-3 \mathrm{Kgs}$ & $6-8 \mathrm{Kgs}$ & \multirow{3}{*}{$\begin{array}{l}\text { The weight of the wooden crates } \\
\text { varies depending on the wood } \\
\text { type and moisture the crate } \\
\text { holds; however its always } \\
\text { assumed to be } 8 \text { kgs. With this } \\
\text { variation, traders often gain } 2-3 \\
\text { kgs of extra free tomato per crate }\end{array}$} \\
\hline $\begin{array}{l}\text { Lifespan and } \\
\text { durability }\end{array}$ & $\begin{array}{l}2-3 \text { years } \\
120-150 \text { loaded trips }\end{array}$ & $\begin{array}{l}1 \text { year maximum } \\
40-50 \text { loaded Trips }\end{array}$ & \\
\hline Capacity & $25-30 \mathrm{Kgs}$ & $50-60 \mathrm{Kgs}$ & \\
\hline Cost & 400 ETB & 200 ETB & \multirow{2}{*}{$\begin{array}{l}\text { Wooden crates are often } \\
\text { overloaded up to } 65-70 \mathrm{Kgs} \text { while } \\
\text { assumed to carry } 60 \mathrm{Kgs} \text {, which } \\
\text { giver traders } 5-10 \mathrm{Kgs} \text { extra } \\
\text { tomatoes for free }\end{array}$} \\
\hline $\begin{array}{l}\text { Space occupied in one } \\
\text { loading car (Isuzu) and } \\
\text { load }\end{array}$ & $\begin{array}{l}157 \text { plastic crates } \\
47 \text { Quintal }\end{array}$ & $\begin{array}{l}84 \text { wooden crates } \\
54 \text { Quintal }\end{array}$ & \\
\hline
\end{tabular}

Figure 2. Advantages of RPCs compared to wooden crates

Estimates of loss reduction from using RPCs for tomatoes vary widely. This is partly because RPCs replace a wide variety of traditional storage tools, from plastic bags to bamboo crates, resulting in different bases against which they are compared. In addition, other factors such as distance to the market, ripeness and temperature during transport are critical to overall loss and tend to vary by location. Regardless, the evidence points to significant loss reduction, as summarised in Table 1.

Table 1. Evidence on the average loss reduction by using RPCs for tomatoes (\%, percentage points)

\begin{tabular}{|c|c|c|c|}
\hline Country & $\begin{array}{l}\text { Status-quo/traditional } \\
\text { instrument }\end{array}$ & $\begin{array}{l}\text { Loss for status-quo/ } \\
\text { traditional instrument, by } \\
\text { weight }\end{array}$ & $\begin{array}{c}\text { Loss for RPC, by } \\
\text { weight }\end{array}$ \\
\hline Afghanistan (21) & Plastic bags & $50 \%$ & $5 \%$ \\
\hline Cape Verde (21) & Shallow crates & $30 \%$ & $10 \%$ \\
\hline Nigeria $(22,23)$ & Raffia woven baskets & $40 \%$ & $5 \%$ \\
\hline Rwanda (24) & Baskets & $30 \%$ & $10 \%$ \\
\hline India (25) & Bamboo basket & $15-20 \%$ & $4-5 \%$ \\
\hline
\end{tabular}


Though evidence on the benefits of RPCs in Ethiopia is sparse, existing data indicates a $50-75 \%$ reduction in losses from using RPCs. ${ }^{4}$ In addition to loss prevention, wholesalers interviewed for this study report that RPCs (compared to wooden crates) double the shelf life of produce, due to better aeration.

\section{BOX 1. STAKEHOLDER VIEWS ON RPC BENEFITS}

Stakeholders interviewed for this assessment saw a range of different benefits to using RPCs at various points throughout the tomato value chain, as illustrated in the following quotes:

- 'We incur a negligible loss when using RPCs to transport tomatoes from the farm to our shop as compared to using wooden crates.' - Wholesaler

- 'Our tomatoes last longer without being spoiled when we use RPCs to store and transport our tomatoes.' - Retailer

- 'Using RPCs to transport tomatoes from farm to market would reduce the loss by $50 \%$ as compared to transporting with wooden crates.' - PHL researcher

- 'RPCs are beneficial compared to wooden crates to the farmers during trade, as the measurement of the RPCs are standardised.' - Manager of a farmers' cooperative

- 'RPCs are more durable, compared to wooden crates, and can be cleaned much more easily.' - Manager of a traders' association

While loss reduction is at the core of RPCs' value, the crates also have broader positive effects for the overall value chain. RPCs standardise measurement of tomatoes across the value chain and therefore level the field for negotiations between sellers and buyers, particularly benefiting farmers. For example, interviewees with traders' associations, farmer cooperatives, and wholesalers noted that intermediaries are often able to overfill wooden crates while only paying for a 'normally loaded' wooden crate's worth of tomatoes-thus getting an estimated 5-10 $\mathrm{kg}$ of additional unpaid-for tomatoes per crate. With expanded use of RPCs and standardised measurements, farmers could increase their earnings by being more accurately compensated for the value they are delivering. Box 1 uses illustrative quotes from stakeholders interviewed for this assessment to demonstrate the range of perceived benefits to using RPCs.

\footnotetext{
${ }^{4}$ Tomato wholesalers based in Addis Ababa indicate that the loss for wooden crates ranges between 15-20\% while transporting tomatoes from Maki to Addis Ababa and around 5-7\% when using RPCs, implying a 50-75\% loss reduction when compared to wooden crates.
} 


\section{CURRENT E-PLAN BUSINESS MODELS AND USERS}

\section{THE TWO E-PLAN PARTNERSHIP MODELS}

E-PLAN distributed RPCs through cooperative unions and traders' associations: cooperative unions Meki-Batu and ODA Agro-Industry received 3,800 and 3,000 RPCs, respectively, and traders' associations Piazza and Arada S.C. received 8,400 and 3,800 RPCs, respectively. Cooperative unions are made up of smaller primary cooperatives: a group of 15 - 20 individual farmers who produce in the same vicinity. Cooperative unions work to support their member farmers by providing training, creating market linkages, and aggregating and selling produce to increase member earnings. Trader associations, on the other hand, are made up of individual wholesalers and retailers that are mostly based in major cities. They support their members by fostering market linkages and engaging in advocacy work but do not take part in the aggregation and sale of produce.

The main differences between the two bodies, and their roles in the value chain, are summarised in Figure 3. The groups were chosen as effective channels for RPCs distribution because they serve as representative bodies of their members. However, their composition is heavily male dominated. ${ }^{5}$ As such, there is an inbuilt gender bias in the E-PLAN participants.

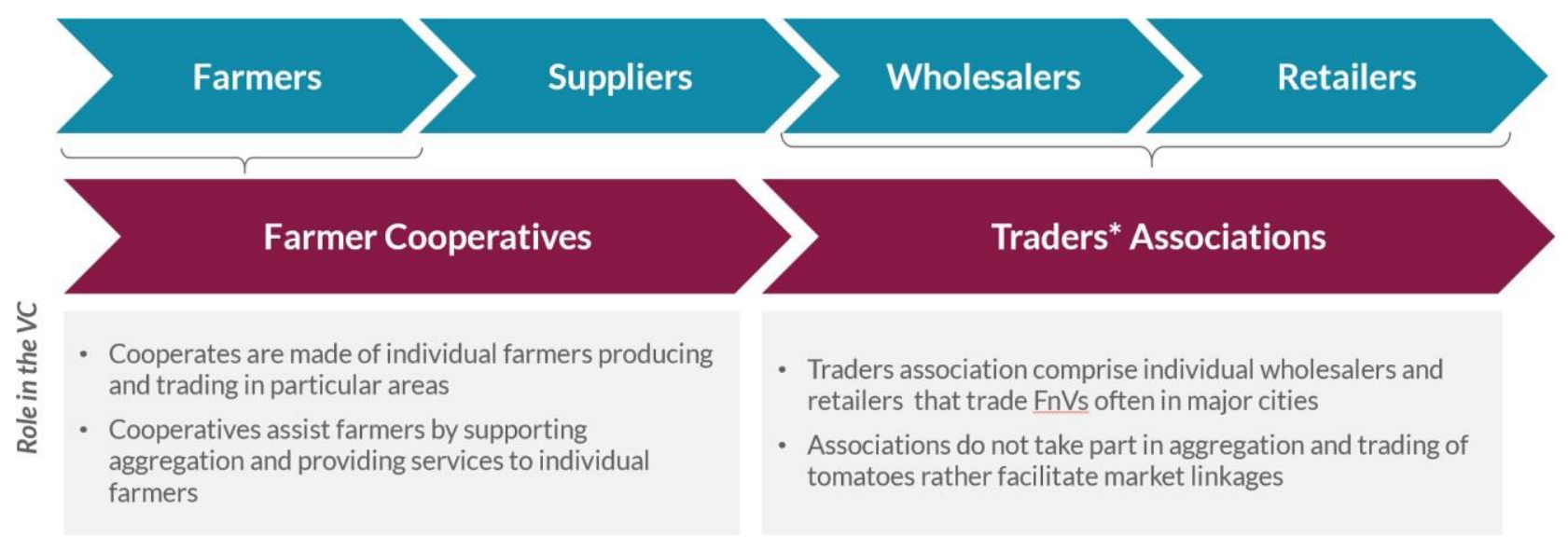

Figure 3. Main E-PLAN partners and their roles

*Note: 'Traders' is used to describe wholesalers and retailers whose role is buying and selling Fruits and Vegetables in the value chain. Source: Stakeholder Interviews; Dalberg analysis

The E-PLAN technical working group initially envisaged that cooperatives and traders' associations would sell RPCs to members at a $50 \%$ discounted price, with the

\footnotetext{
${ }_{5}^{5}$ While accurate data is not available on the gender breakdown of individuals involved in the tomato value chain, the traders' associations and co-op unions have indicated that almost all their members are men. This is corroborated by a recent $\mathrm{FAO}$ report on the topic (26).
} 
assumption that individual users would ultimately pay for and own crates. ${ }^{6}$ However, each group was able to decide upon its own distribution model, so the distribution models actually used diverged from this plan: farmer cooperatives developed a rental model and traders' associations distributed RPCs on credit to members. The next subsections explore each of these models in more detail.

\section{DISTRIBUTION MODEL 1: FARMER COOPERATIVES MODEL}

In the model used by the cooperatives, the cooperatives own the crates and lend them to farmers on-demand, and they are returned to the cooperative after use. Cooperatives view the provision of RPCs as a way of strengthening the services provided to member farmers by enabling them to earn more for their tomatoes.

How this model works is illustrated in Figure 4. First, member farmers request RPCs from the cooperative. In return, the cooperatives provide the crates to the requesting member and charge a service fee of 1,000 ETB (about 25 USD) per truckload of crates. ${ }^{7}$ This fee applies equally across wooden and plastic crates and includes the use of warehouse storage and weighing facilities. For identification and tracking purposes, cooperatives number and mark the RPCs with their name. Once in possession of the RPCs, farmers load them with produce and typically transfer the tomatoes to cooperative-owned wholesalers or retailers. In some cases, the farmers instead transfer the tomatoes to traders' associations; this happens only when the cooperative has an explicit off-taker agreement with the traders' association, ensuring the RPCs are traceable. Finally, wholesalers and retailers (or, in rare cases, trader's associations) return cleaned RPCs to the cooperatives, which then re-start the process. ${ }^{8}$

\footnotetext{
6 Traders associations and farmers cooperatives were not expected to pay GAIN for the RPCs. Rather, it was agreed that income from recipients would be used to finance purchase of additional RPCs.

7 This fee is a standard cooperative service fee and did not change with the introduction of RPCs. There are typically $\sim 84$ wooden crates $(5,040 \mathrm{~kg}$ per load) or $\sim 157$ plastic crates $(4,710 \mathrm{~kg}$ per load) in a single load.

8 Individual farmers, wholesalers, retailers who misplace or damage RPCs are liable for replacement costs, with risk primarily managed through relationships.
} 


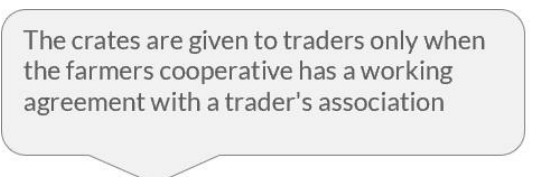

\section{Individual Wholesalers/Retailers}

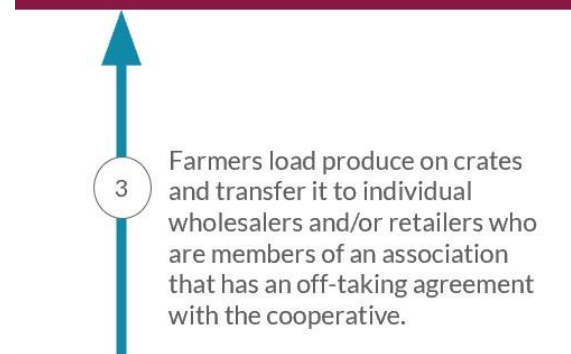

Individual wholesalers use the crates and then clean and return crates to

cooperatives

Cooperatives own the crates - in this case

through crates donated through PLAN

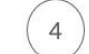

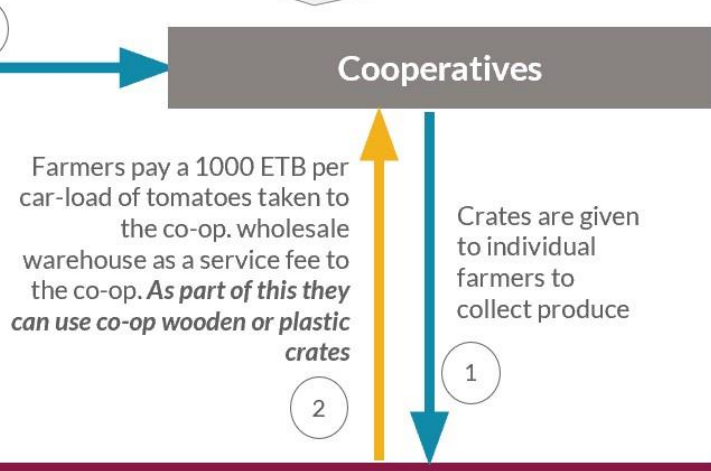

Farmers

Revenue model: Farmers pay for the RPCs per loaded trip as part of a broader services from cooperatives.

Crate users

Crate owners

Crate Flow Flow of payment for crate

Figure 4. Farmer cooperatives RPC business model

\section{The model adopted by cooperatives encourages early uptake by lowering the cost of RPCs while demonstrating to users RPCs' benefits.}

The model adopted by the cooperatives has potential benefits: it lowers the cost of RPCS while demonstrating RPCs' benefits to users. Since technology adoption is improved when value chain actors can experiment and see the value-added by a new tool without bearing significant additional costs (27), cooperatives' approach of circulating RPCs at the same cost as wooden crates may be beneficial in the early stages of RPC introduction and adoption. There are potential drawbacks, however. If cooperatives do not charge additional fees to rent out the RPCs, there is a risk they will not build the capital needed to purchase additional RPCs to eventually replace wooden crates (and any RPCs that are degraded over time). There is also a risk of RPC shortages during high season, since cooperatives serve multiple farmers who all tend to harvest at the same time. 9

To ensure long-term financial sustainability, farmer cooperatives could charge more for the RPCs. We estimate that farmers currently using RPCs earn an extra 2,000 - 5,000 ETB per loaded trip (i.e., 157 RPCs packed with tomatoes), as illustrated in Figure 5.10 This suggests that, as the benefits of RPCs become well established, farmer cooperatives could charge extra for the use of RPCs while still allowing farmers to reap higher profits. Additional charges would not need to be high: a simple, conservative estimate (see Appendix Table A4) suggests that by charging an additional 50 ETB per

\footnotetext{
${ }^{9}$ To manage this risk, cooperatives would need to identify a minimum number of RPCs needed to meet all user demands and ensure rapid return of RPCs.

10 Revenue per trip will vary significantly depending on prevailing seasonal prices.
} 
use, cooperatives would have more than enough revenue to replace and buy additional RPCs over the course of 3 years, enabling overall financial sustainability for the model.

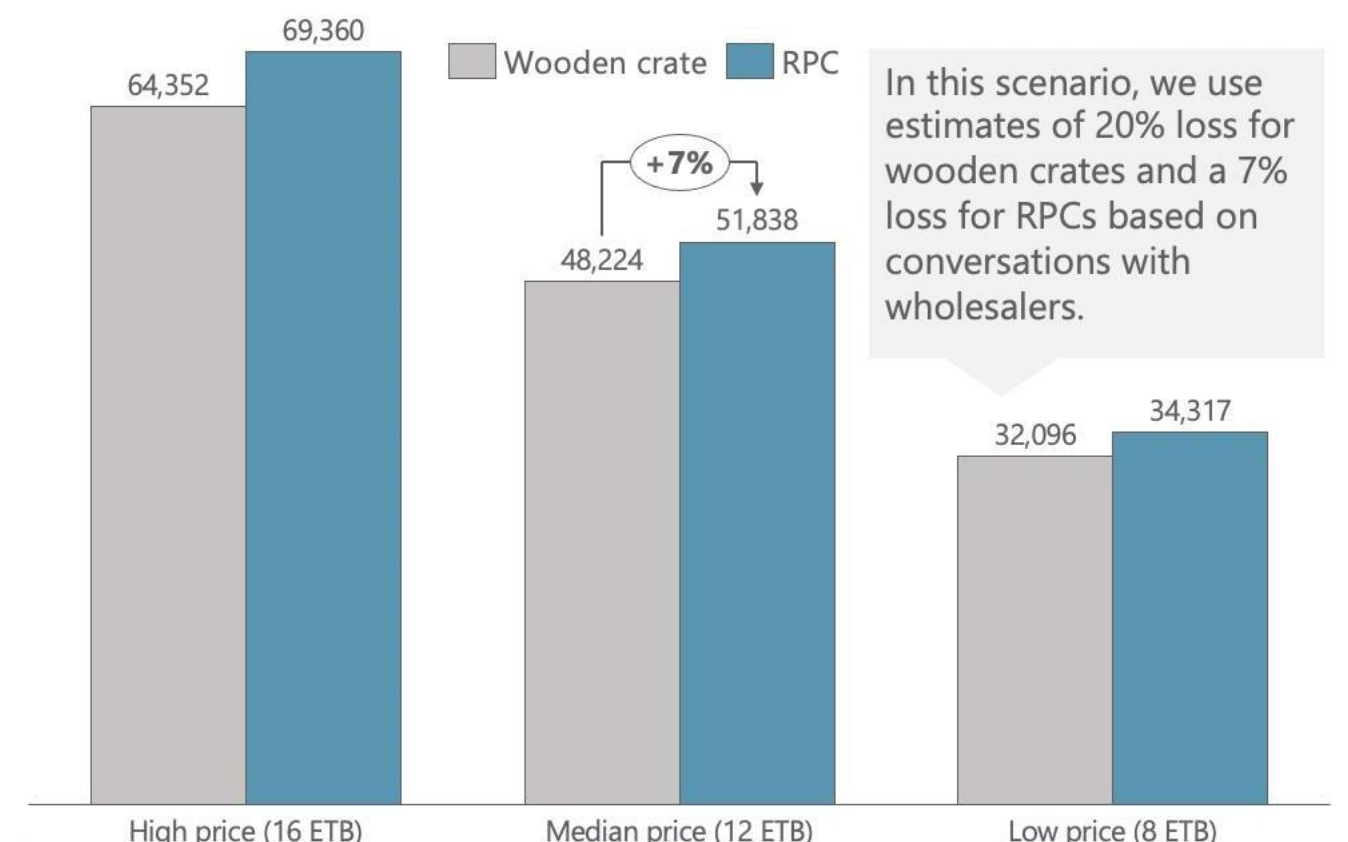

Figure 5. Analysis of additional profit to farmers using RPCs under various wholesale price scenarios (in ETB per trip)

Note: prices capture the range in price noted in interviews; fluctuations are largely a result of changes in relative tomato supply and demand

\section{DISTRITBUTION MODEL 2: TRADERS’ ASSOCIATIONS MODEL}

Traders' associations permanently transfer ownership of RPCs to their members, either at a subsidised price or for a deferred payment. Piazza Traders' Association sells the crates to their members at a $50 \%$ subsidised fee, while Arada Traders' Association distributes the RPCs free of charge on credit, with the expectation that payment will follow. "Individual wholesalers, either independently or through a supplier, take the RPCs to a farm or wholesale centre to load and transport tomatoes. ${ }^{2}$ Wholesalers generally own the tomatoes stored in the RPCs during transportation from the farm and thus benefit from the loss reduction that RPCs offer. Wholesalers mark the crates with their names for identification purposes and are responsible for cleaning and

\footnotetext{
11 Because the RPCs were distributed during the COVID-19 pandemic, many farmers and wholesalers were suffering from lower-than normal revenues; the traders' association's assumption was that they would be repaid once business picks up post-pandemic.

${ }^{12}$ Approaches to transferring tomatoes from wholesaler to retailer differ. In some instances, tomatoes are transferred in the crate, where in others they are transferred loosely. Where there is not a close relationship between the wholesaler and retailer, wholesalers prefer not to transfer the RPC due to concerns about them not being returned.
} 
maintaining the crates. Figure 6, below, summarises the RPC business model used by trader associations.

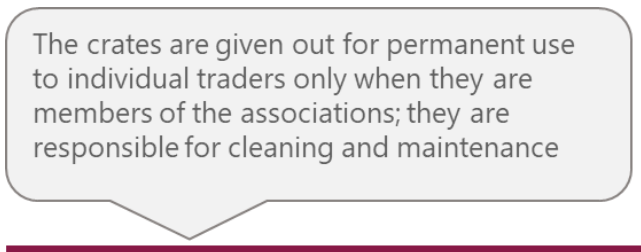

Individual Wholesalers/Retailers

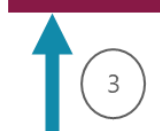

Individual traders take the crates to farmers (or send the crates via a transporter to load tomatoes).

Wholesaler bear the risk of tomato damage

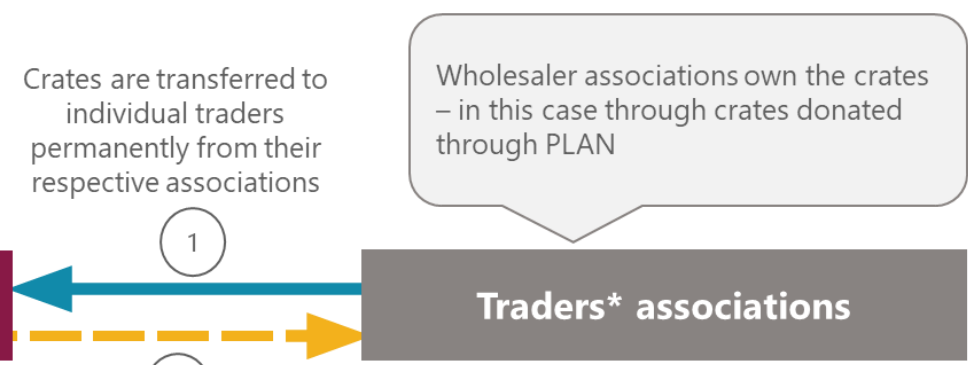

2 (2)

Some traders pay $50 \%$ of the price to associations, Piazza SC in particular; others are given RPCs free of charge, E.g Arada SC

\section{Farmers}

Revenue model: Some traders buy the RPCs from associations at 50\% price (Piazza SC) while others are given RPCs free of charge (E.g Arada SC)

Crate users Crate owners

$\rightarrow$ Crate Flow

Flow of payment for crate

Figure 6. Traders' Associations' RPC distribution and usage model

The model has powerful demonstration effects but is likely not sustainable.

Distributing RPCs for a deferred and subsidised payment is highly beneficial for demonstrating the efficacy of RPCs to wholesalers amidst a slow market. However, in the absence of outside support, this subsidised pricing model is likely financially unsustainable in the long run. Associations are unlikely to be able to subsidise RPCs out of regular membership fees, and purchasing replacements will be a challenge if there is no cashflow from RPC sales.

As shown in Figure 7, wholesalers earn significantly more when using RPCs. This suggests that associations could feasibly sell RPCs at higher prices, particularly if appropriate financing instruments were available. With this extra earning, an average wholesaler selling about 4-5 carloads of produce would be able to cover the initial investment in purchasing RPCs after 14-16 trips of tomato sales. This makes it feasible that associations could sell RPCs to wholesalers at cost or at a small profit, thereby ensuring their financial sustainability. ${ }^{13}$ As part of this, associations could negotiate bulk discounts, passing savings on to members and strengthening their positions as a result.

13 Willingness to pay would need to be explored on a case-by-case basis; wholesalers were non-committal in this regard during interviews. 
The model would be greatly strengthened by appropriate asset financing options for wholesalers. It would cost upwards of 200,000 ETB ( 5,000 USD) for the average wholesaler to completely shift their stock of wooden crates to RPCs (though such a shift could also take place gradually, if such a large amount of money was not available all at once). ${ }^{14}$ At present, credit is expensive and often inaccessible, so the investment would have to be financed out of pocket - a challenge for many.

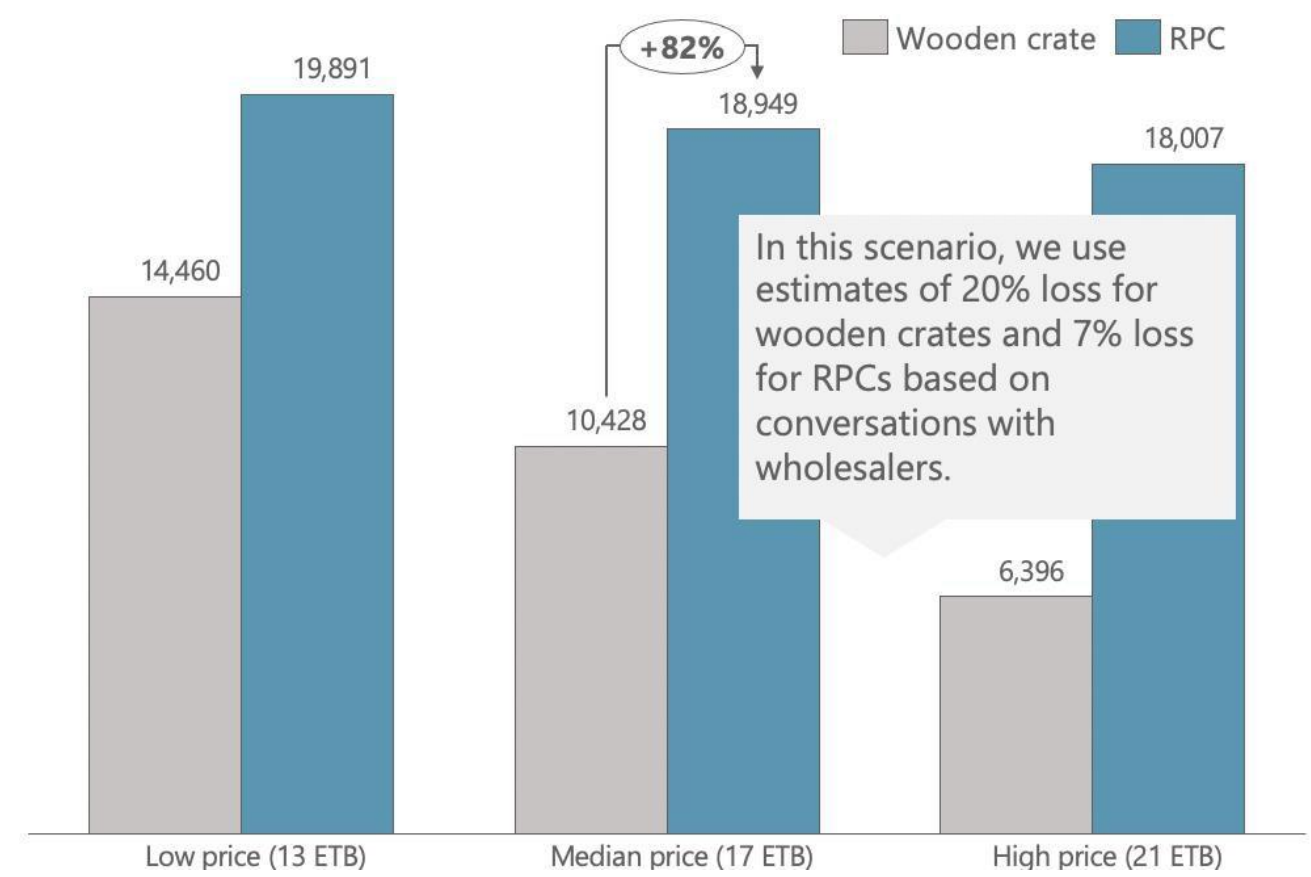

Figure 7. Analysis of additional profit to wholesalers under various retail price scenarios (in ETB per trip)

Note: prices capture the range in price noted in interviews; fluctuations are largely a result of changes in relative tomato supply and demand

\section{BROADER CHALLENGES TO RPC UPTAKE IN ETHIOPIA}

Through analysis of the tomato value chain, this assessment identified three main challenges to RPC uptake in Ethiopia: (i) barriers to ownership and usage of RPCs due to high cost, (ii) market norms rooted in the use of wooden crates and limited awareness, and (iii) weak regulatory enforcement. While the challenges described here were identified based on an in-depth analysis of the tomato value chain, many are applicable to horticultural value chains in Ethiopia in general, and many tomato farmers and wholesalers also grow or sell a variety of fruits and vegetables.

\section{BARRIERS TO OWNERSHIP AND USAGE}

While farmers and wholesalers generally prefer RPCs (see Box 1), their high cost is the primary barrier to ownership. RPCs are both more expensive and have a smaller

14 The average wholesaler owns about 400 wooden crates. 
capacity than wooden crates, necessitating a high upfront investment to switch to RPCs. The price of an RPC ranges from 180 - 400 ETB, depending on size, type, and whether purchased at the factory or in retail; if one is able to purchase standard-size RPCs from the manufacturer, the price may be lower, around 180-200 ETB. Wooden crates cost between 150 - 200 ETB for a crate around twice the size. The high price has a knock-on effect on rental usage of RPCs: the deposit for renting an RPC is about 200 ETB, significantly higher than the $50-100$ ETB for a wooden crate. Moreover, as an RPC's capacity is half that of a wooden crate, value chain actors must purchase or rent twice as many RPCs as wooden crates to move the same volume of produce. ${ }^{15}$ Though not as significant, RPCs also entail a cleaning cost, which is not needed for wooden crates. Finally, while RPCs typically last 2 to 3 times longer than wooden crates, when RPCs do break, they are typically far harder to repair. While this should not be a concern if RPCs are high-quality and durable, it could make lower-quality RPCs significantly less attractive to users.

\section{MARKET SYSTEM INERTIA}

In addition, inertia from value chain participants that are comfortable with and benefit from the status quo of using wooden crates is hindering the adoption of RPCs at scale. Wooden crates are entrenched in the tomato value chain's trading systems and norms. Transactions are currently measured using the standard size of wooden crates; introducing RPCs entails changing this transaction structure. Furthermore, wholesalers benefit from using wooden crates because they can overload them when purchasing at the farm and then re-pack new (less full) crates when selling them. These practices disincentivise wholesalers and retailers from adopting RPCs and indirectly make their suppliers risk-averse to using RPCs for fear of losing demand. More broadly, limited awareness on RPCs' benefits, especially among small- and mediumscale value chain actors, continues to hinder widespread uptake.

\section{REGULATORY ENFORCEMENT}

In Ethiopia's fragmented, informal tomato value chain and overall weak regulatory environment, designing the right regulatory framework and enforcement mechanism for use of RPCs remains a challenge. While rules regarding the safe transport and storage of perishable food have been developed and endorsed, they are not enforced. This is likely a function of informal fragmented value chains being difficult to monitor, limited pressure from price-sensitive lower-income consumers, and the expense of meeting the regulatory standards.

15 Overall, while farmers and wholesalers typically value RPCs - they were non-committal about their willingness to invest in them, citing these high-costs. 


\section{DISCUSSION}

\section{ADAPTING RPC MODELS FOR IMPROVED SUSTAINABILITY}

While the distribution models examined here encourage uptake, without an outside subsidy they are financially unsustainable for the groups in question-and thus not a long-term route to sustained RPC adoption. However, as farmers and wholesalers using RPCs through these groups are earning extra from reduction in tomato losses or selling higher quality fruit at a higher price, there are opportunities to adapt the models to enable sustainability. Two other business models for RPC utilisation have been documented in the literature, as summarised in Figure 8. In the first model, RPCs are independently owned and used by each value chain player (28). This is especially common for larger commercialised value chain players, which are often vertically integrated. In Ethiopia, several large commercial farmers already own RPCs that they use for the transport of fresh produce. In informal value chains, however, the commonly used wooden crates are typically owned by either wholesalers or farmer cooperatives.

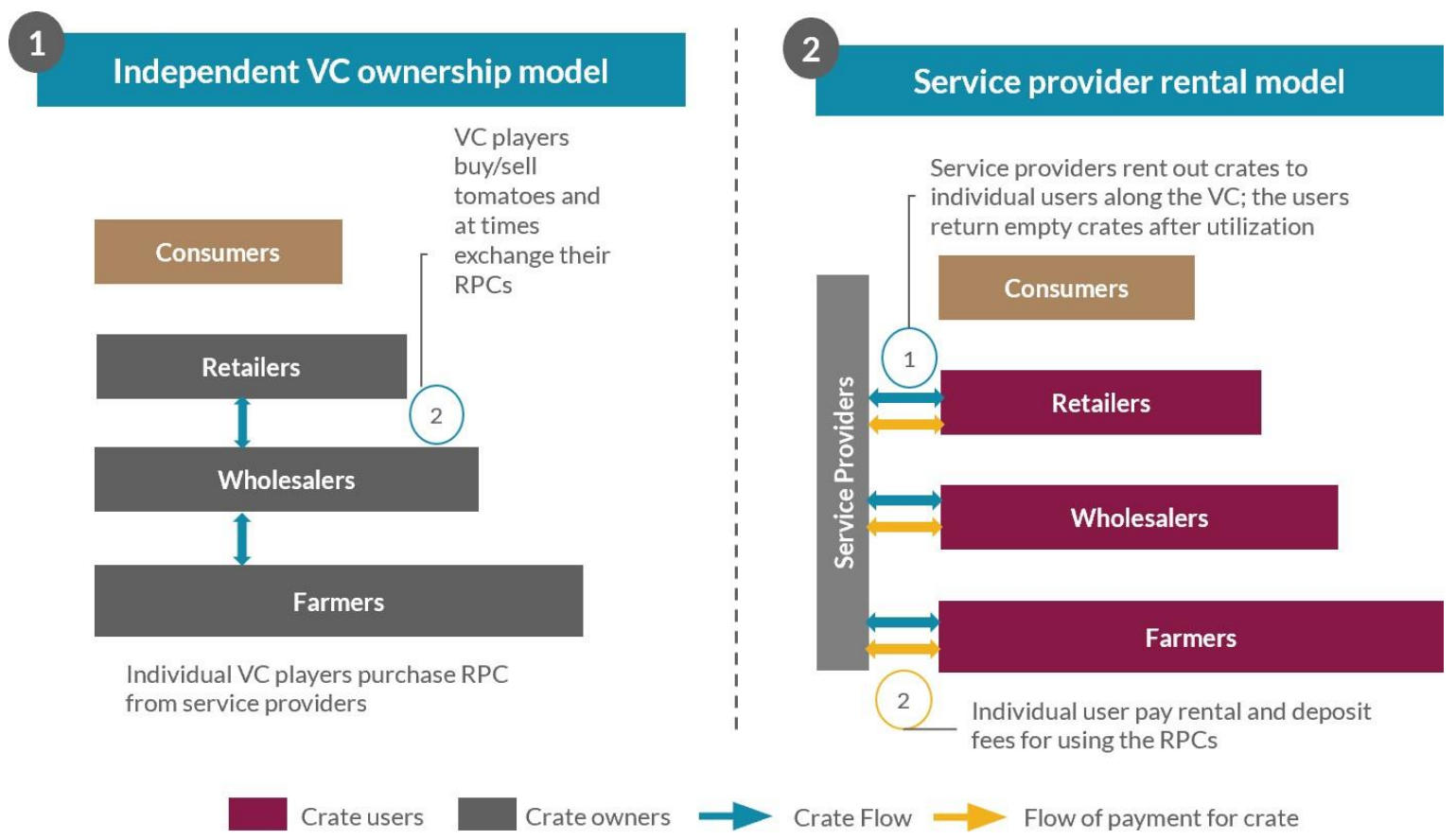

Figure 8. Overview of alternative RPC business models

The second model entails a dedicated service provider renting out crates to users along the value chain, including to commercial buyers such as restaurants. Though not popular in Ethiopia, RPC rental services are common in Europe and several African markets, including Nigeria (29). These rental service providers often rent out a 
large number of RPCs, using a rental fee and deposit system. ${ }^{16}$ The circulating RPC model used by cooperatives in Ethiopia is similar to this service model, with two differentiating factors marking the cooperatives' model: (i) farmers do not pay a rental and deposit fee specifically for using RPCs (they pay the same fee for wooden crates as for RPCs, and the fee is for a broader set of services), and (ii) risk is minimal as crates circulate within a known group of farmers. Cooperatives could potentially adopt this model and act as a service provider to member farmers and non-member users and leverage the proceeds to strengthen other support areas. There are thus reasonable options for improving the financial sustainability of the RPC models examined here.

\section{IMPROVING FUTURE PHL-REDUCTION APPROACHES}

In addition to refining business models, we see two options for strengthening interventions similar to E-PLAN in the future. First, RPCs have cross-cutting relevance, so future efforts to encourage uptake could be coordinated across value chains. While E-PLAN focused specifically on tomatoes, RPCs have significant benefits for a wide range of fruits and vegetables - such as avocado, mango, papaya, and aubergine. Many of these have similar value chain structures, with products being sold through wholesalers in urban markets and farmer cooperatives supporting smallholder aggregation. This means that RPCs distributed for use in tomato value chains are also often used by the same actors in other fruit and vegetable value chains. Taking a value chain-agnostic approach to the distribution of RPCs could thus increase feasibility of adoption and impact by fostering economies of scale and partnerships among actors currently working on PHL in specific value chains. As these value chains contribute to improving diets, livelihoods, and/or the environmental burden of $\mathrm{PHL}$, such interventions would have positive impacts on nutrition, economic, or environmental development outcomes. In practice this could entail distributing RPCs through actors that straddle multiple value chains, such as wholesalers or crossproduct cooperatives.

Another area for strengthening PHL-reduction interventions in the future is by a more explicit focus on gender sensitivity. Working through cooperatives and traders' associations, which have overwhelmingly male membership, biases intervention impact towards benefiting men-even though women are active throughout Ethiopia's food system. Future interventions can aim to work with individual female farmers, wholesalers, and retailers, but this would likely be inefficient and less costeffective. Working with women's groups may be an option, or gender quotas or targets could be used to place pressure on cooperatives and associations to more deliberately include women as members and in leadership positions. Similarly, messaging on the importance of participation of and leadership by women - which

16 In some cases, farmers in Ethiopia rent out about 3 -5 RPCs at a daily rate to measure less fragile produce, such as onions, when loading it into a car. The renting out of crates for transport and storage has not been observed. 
could be included in trainings or communications materials - could help reinforce the importance of being gender inclusive. It will also be important to include women as active participants in designing interventions and to work to address underlying structural barriers, such as unequal gender norms (30). Finally, complementary interventions could work with women in the parts of the value chain where they may already be active or could more easily engage (e.g., microscale proximate processing).

\section{ADDRESSING BROADER BARRIERS TO RPC UPTAKE}

At a broader level, high cost is a critical barrier to RPC uptake within Ethiopia. One way to do this would be by developing financial instruments to encourage RPC adoption. RPCs are inherently a profitable investment and therefore an attractive proposition against which to lend, and a financing instrument could mitigate the high upfront costs and thus support RPC uptake. One potential option would be a line of credit to associations, which could then be lent on to traders and famers. Loan payments could be bundled with yearly fees or structured into a series of payments post-high season. As the representative bodies understand their members well, this would lower transaction costs and likely remove the need for collateral. For this to succeed, it would be necessary to identify a financial partner willing to provide affordable credit and to ensure that the association has the capacity to appropriately manage the lending.

A second way to lower the cost barrier would be to engage with government and manufacturers to reduce the cost of RPCs and strengthen their accessibility. Currently RPCs are imported or rely on imported inputs, marking an opportunity to engage with government to reduce import tariffs to improve food security and sustainability. If these actions were coupled with commitments by manufacturers to pass on savings to end-users, this could reduce the RPC price paid by farmers and wholesalers.

To be financially viable, interventions to reduce costs and improve access must be complemented by increased demand-which can be partly enabled by addressing challenges in systemic inertia. Systemic change in market norms could be best realised by creating a critical mass of early RPC adopters through subsidised and targeted programmes. Technology diffusion tends to follow an S-curve: towards the left of the curve, the rate of adoption of is slow, as potential users are sceptical of benefits, but once a critical mass of users is reached, the rate of adoption increases rapidly. At present, we conservatively estimate the penetration of RPCs vis-à-vis wooden crates in Ethiopia's informal sector to be less than 1\%, well below the 'critical mass' of $10-20 \%$ typically quoted in the literature (31). ${ }^{17}$ Given this, there may be merit in subsidising the disbursement of RPCs to help shift RPC penetration to the point where adoption accelerates of its own accord. Subsidising products and awareness-

17 See annex for calculation 
creation programmes is an effective way of encouraging uptake and assimilating new tools into existing systems (27). In this case, it could be used to build awareness and demonstrate the benefits of RPCs and familiarise actors with RPCs as a tool of measurement in the market, without significant cost or risk to end users. In addition, expanding the number of RPC users would reduce the bargaining power available to the individuals benefitting from the status quo of wooden crates, limiting their ability to continue dictating market norms.

\section{CONCLUSION}

Reduction of post-harvest loss is a promising way to make nutritious foods more available, accessible, and affordable-all while improving the sustainability of the food system. While viable technologies to reduce PHL exist, they have limited uptake. To understand how to increase their use, this paper examined business models for distributing Reusable Plastic Crates (RPCs) within Ethiopia's tomato value chain. Based on stakeholder interviews and a literature review, we assessed evidence on the benefits of RPCs and types of business models deployed in both Ethiopia and globally. We found that RPCs are beneficial in reducing post-harvest loss, including for tomatoes, and have wider systemic benefits for the overall value chain, including introducing standardised measurements, which may improve transaction fairness. However, the two RPC distribution models examined here were found to be not sustainable in the long term, as insufficient revenue is earned to replace or purchase additional RPCs. Moreover, RPC adoption at scale is hindered by barriers to RPC ownership, market systems inertia, and weak regulation, and prior interventions have generally been biased towards male farmers and wholesalers.

There are several steps that business owners and development partners can take to address these challenges, including gender-inclusive intervention design; making affordable, flexible financing more available; reducing RPC cost; and leveraging wholesalers as an entrance point to encourage wider adoption across diverse value chains. Investing in developing, testing, and scaling up these interventions could reap large benefits in terms of reducing the currently high levels of loss found in Ethiopia's fresh fruit and vegetable value chains - with positive ramifications for nutrition and the environment, alike. 


\section{REFERENCES}

1. UNICEF, WHO, World Bank. Levels and trends in child malnutrition: Key Findings of the 2020 Edition of the Joint Child Malnutrition Estimates. Geneva: World Health Organization; 2020.

2. GAIN, UNICEF. Comprehensive Nutrient Gap Assessment (CONGA): Findings for children 6-23 months in Ethiopia. Geneva: Global Alliance for Improved Nutrition (GAIN); 2019.

3. Ethiopian Public Health Institute. Ethiopian National Food Consumption Survey [Internet]. Addis Ababa: Ethiopian Public Health Institute; 2013. Available from: https://www.ephi.gov.et/images/pictures/National\%20Food\%20Consumption\%20 https://www.ephi.gov.et/images/pictures/National\%20Food\%20Consumption\%20 Survey\%20Report_Ethiopia.pdf

4. Central Statistical Agency - CSA/Ethiopia, ICF. Ethiopia Demographic and Health Survey 2016 [Internet]. Addis Ababa, Ethiopia: CSA and ICF; 2017. Available from: http://dhsprogram.com/pubs/pdf/FR328/FR328.pdf

5. Sommer A. Vitamin A deficiency and its consequences: a field guide to detection and control. Geneva: World Health Organization; 1995.

6. FAO. Postharvest Extension Bulletin. Issue: January - March 2019. Addis Ababa: FAO Office in Ethiopia; 2019.

7. United Nations, Department of Economic and Social Affairs, Population Division. World Population Prospects: The 2019 Revision. New York: United Nations, Department of Economic and Social Affairs, Population Division; 2019.

8. Affognon $\mathrm{H}$, Mutungi $\mathrm{C}$, Sanginga $\mathrm{P}$, Borgemeister $\mathrm{C}$. Unpacking Postharvest Losses in Sub-Saharan Africa: A Meta-Analysis. World Development. 2015 Feb;66:49-68.

9. Committee on Food Security. Post-harvest losses: Prevention is the cure. [Internet]. Available from: http://www.fao.org/cfs/home/blog/blogarticles/article/en/c/1052829

10. FAO. The State of Food and Agriculture 2019 [Internet]. Food and Agriculture Organisation of the United Nations; 2019 [cited 2020 Jul 30]. Available from: http://www.fao.org/documents/card/en/c/ca6030en

11. Sheahan M, Barrett CB. Review: Food loss and waste in Sub-Saharan Africa. Food Policy. 2017 Jul;70:1-12.

12. Abbade EB. Estimating the nutritional loss and the feeding potential derived from food losses worldwide. World Development. 2020 Oct;134:105038.

13. United Nations Development Programme. Sustainable Development Goals. [Internet]. 2020. Available from:

https://www.undp.org/content/undp/en/home/sustainable-developmentgoals.html 
14. Yalch T, Lofthouse J, Nordhagen S. Creating alliances and fostering innovations to reduce postharvest food loss: Experiences from GAIN's Postharvest Loss Alliances for Nutrition [Internet]. Global Alliance for Improved Nutrition (GAIN); $2020 \mathrm{Sep}$ [cited 2020 Oct 5]. Available from:

https://www.gainhealth.org/sites/default/files/publications/documents/gainworking-paper-series-9-creating-alliances-and-fostering-innovations-to-reducepost-harvest-loss-of-nutritious-food.pdf

15. Dalberg Consulting. PLAN Ethiopia: Summary Note of Findings on Postharvest Loss in the Tomato, Mango and Papaya Value Chains. New York: Dalberg Advisors; 2018 Sep.

16. FAO. The State of Food and Agriculture 2019. Moving forward on food loss and waste reduction. Rome: Food and Agriculture Organization of the United Nations; 2019.

17. Rapusas RS, Rolle RS. Management of reusable plastic crates in fresh produce supply chain [Internet]. Rome: Food and Agriculture Organization of the United Nations; 2009. Available from: http://www.fao.org/3/i0930e/i0930e00.pdf

18. Obanubi M, Okoruwa A, Morris S, Nordhagen S, Wouabe ED, Yalch T. Business opportunities to reduce post-harvest loss of nutritious foods: Modelling the return on investment of field-ready technologies in Nigeria. Geneva, Switzerland: Global Alliance for Improved Nutrition (GAIN); 2021. Working Paper \# 16.

19. CSA. Report on area and production of major crops, 2017/2018. Addis Ababa: Central Statistical Agency of Ethiopia (CSA); 2018.

20. USDA. USDA National Nutrient Database for Standard Reference, Release 21 [Internet]. Washington, DC: U.S. Department of Agriculture, Agricultural Research Service.; 2008. Available from: http://www.ars.usda.gov/nea/bhnrc/mafcl

21. Kitinoja L. Returnable Plastic Crate (RPC) systems can reduce postharvest losses and improve earnings for fresh produce [Internet]. The Postharvest Education Foundation; 2013 Apr. Report No.: White Paper No. 13-01. Available from: http://www.postharvest.org/RPCs\%20PEF\%202013\%20White\%20paper\%201301\%20pdf\%20final.pdf

22. Kok MG, Groot JJ, Dastoum S, Plaisier C, Dijkxhoorn Y, Wagenberg CPA van. A Measurement tool on Food losses and Waste: Applied in a tomato value chain in Nigeria. Wageningen: Wageningen University \& Research; 2019.

23. Benson OB, Ambee IA, Osegbo AN, Okonkwo EU. Re-useable plastic crates as a veritable tool for handling of fresh fruits and vegetables: Lagos State as a case study. Journal of Stored Products and Postharvest Research. 2020;11 (1).

24. USAID Feed the Future. PHL assessment of tomatoes in Rwanda. Washington, DC: United States Agency for International Development (USAID); 2018. 
25. World Economic Forum. Enabling Trade: From Valuation to Action [Internet]. Geneva, Switzerland: World Economic Forum; 2014 Jan. Available from: http://www3.weforum.org/docs/WEF_EnablingTradeReport_2014.pdf

26. Brasesco F, Asgedom D, Casari G. Strategic analysis and intervention plan for fresh and industrial tomato in the Agro-Commodities Procurement Zone of the pilot Integrated Agro-Industrial Park in Central-Eastern Oromia, Ethiopia. Addis Ababa: Food and Agriculture Organization of the United Nations; 2019.

27. Omotilewa OJ, Ricker-Gilbert J, Ainembabazi JH. Subsidies for Agricultural Technology Adoption: Evidence from a Randomized Experiment with Improved Grain Storage Bags in Uganda. American Journal of Agricultural Economics. 2019 Apr;101(3):753-72.

28. Plaisier C, Sibomana M, Van der Waal J, Clercx L, Van Wagenberg CPA, Dijkxhoorn Y. Approach for Designing Context-Specific, Locally Owned Interventions to Reduce Postharvest Losses: Case Study on Tomato Value Chains in Nigeria. Sustainability. 2019 Jan 7;11 (1):247.

29. Lawal K. The Returnable Plastic Crate rental model - Increasing Returnable Plastic Crates access to reduce Post-Harvest Losses in fresh perishables [Internet]. 2017 [cited 2021 Jan 6]. Available from: https://grandespinale.medium.com/thereturnable-plastic-crate-rental-model-increasing-returnable-plastic-cratesaccess-to-reduce-704elbdfd7e8

30. Cole SM, Kaminski AM, MCDougall C, Kefi AS, Marinda PA, Maliko M, et al. Gender accommodative versus transformative approaches: a comparative assessment within a post-harvest fish loss reduction intervention. Gender, Technology and Development. 2020 Jan 2;24(1):48-65.

31. Rogers EM. Diffusion of innovations. 5th ed. New York: Free Press; 2003. 551 p. 


\section{ANNEX}

\section{ADDITIONAL DATA SUPPORTING THE PAPER'S ANALYSIS}

Tables A3 and A4, below, summarise the number of wooden crates currently circulating among fruit and vegetable traders in Addis Ababa and an estimate of additional costs needed to replace RPCs over time, based on the business model of one of the E-PLAN partner cooperatives.

Table A3. Estimated number of wooden crates circulating among fruit and vegetable traders in Addis Ababa

\begin{tabular}{|l|c|}
\hline Number of associations & 10 \\
\hline Avg. number of wholesalers in each association & 100 \\
\hline Total number of wholesalers & 1000 \\
\hline \% of large wholesalers & $20 \%$ \\
\hline \% of mid-level wholesalers & $30 \%$ \\
\hline$\%$ of small wholesalers & $50 \%$ \\
\hline Avg. number of crates owned by a large wholesaler & 800 \\
\hline Avg. number of crates owned by a mid-level wholesaler & 400 \\
\hline Avg. number of crates owned by a small wholesaler & 200 \\
\hline Total number of crates owned by large wholesalers & 160,000 \\
\hline Total number of crates owned by mid-level wholesalers & 120,000 \\
\hline Total number of crates owned by small wholesalers & 100,000 \\
\hline Total number of wooden crates & 380,000 \\
\hline
\end{tabular}

Table A4. Estimate of additional costs needed to replace RPCs over time, from Cooperative A Business Model Estimate

\begin{tabular}{|l|c|}
\hline Number of crates & 3,800 \\
\hline Cost per crate & 200 \\
\hline Additional payment per use (ETB) & 50 \\
\hline Number of members & 8,300 \\
\hline Number uses per member per year & 1 \\
\hline Yearly revenue from additional (ETB) & 415,000 \\
\hline Number crates per year from additional revenue & 2,075 \\
\hline Number crates from 3 years' revenue & 6,225 \\
\hline
\end{tabular}

